\title{
Risk Indicators for Tooth Loss Due to Periodontal Disease
} Khalaf F. Al-Shammari, ${ }^{*}$ Areej K. Al-Khabbaz, ${ }^{*}$ Jassem M. Al-Ansari, ${ }^{\dagger}$ Rodrigo Neiva, ${ }^{\dagger}$
and Hom-Lay Wang ${ }^{\ddagger}$

Background: Several risk indicators for periodontal disease severity have been identified. The association of these factors with tooth loss for periodontal reasons was investigated in this cross-sectional comparative study.

Methods: All extractions performed in 21 general dental practice clinics (25\% of such clinics in Kuwait) over a 30 day period were recorded. Documented information included patient age and gender, medical history findings, dental maintenance history, toothbrushing frequency, types and numbers of extracted teeth, and the reason for the extraction. Reasons were divided into periodontal disease versus other reasons in univariate and binary logistic regression analyses.

Results: A total of 1,775 patients had 3,694 teeth extracted. More teeth per patient were lost due to periodontal disease than for other reasons $(2.8 \pm 0.2$ versus $1.8 \pm 0.1$; $P<0.001)$. Factors significantly associated with tooth loss due to periodontal reasons in logistic regression analysis were age $>35$ years (odds ratio [OR] 3.45; 95\% confidence interval $[\mathrm{CI}] 2.79$ to 4.26 ), male gender (OR $1.42 ; 95 \% \mathrm{CI} 1.17$ to 1.73), never having periodontal maintenance (OR 1.48; 95\% CI 1.23 to 1.78 ), never using a toothbrush (OR $1.81 ; 95 \% \mathrm{CI}$ 1.49 to 2.20 ), current or past smoking (OR 1.56; 95\% CI 1.28 to 1.91 ), anterior tooth type (OR $3.23 ; 95 \%$ CI 2.57 to 4.05), and the presence of either of the following medical conditions: diabetes mellitus (OR 2.64; 95\% CI 2.19 to 3.18), hypertension (OR 1.73; 95\% CI 1.41 to 2.13 ), or rheumatoid arthritis (OR 4.19; 95\% CI 2.17 to 8.11 ).

Conclusion: Tooth loss due to periodontal disease is associated with the risk indicators of age, male gender, smoking, lack of professional maintenance, inadequate oral hygiene, diabetes mellitus, hypertension, rheumatoid arthritis, and anterior tooth type. J Periodontol 2005;76:1910-1918.

\section{KEY WORDS}

Diabetes mellitus; periodontal disease; risk indicators; smoking; tooth loss.

\footnotetext{
* Specialized Center for the Advancement of Dental Services, Ministry of Health, Jahra Kuwait.

$\uparrow$ College of Health Sciences, Shuwaikh, Kuwait.

$\ddagger$ Department of Periodontics/Prevention/Geriatrics, School of Dentistry, University of Michigan, Ann Arbor, MI.
}

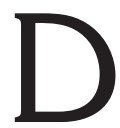
ue to the recognition that severe periodontal disease affects a certain group of individuals that appear to exhibit increased susceptibility to periodontal destruction, ${ }^{1-3}$ several studies have attempted to identify systemic and local factors that may identify these high-risk individuals. ${ }^{4-8}$ Risk assessment studies have identified several subject level characteristics including age, male gender, smoking, and diabetes mellitus as being associated with periodontal disease severity and/or progression as measured by attachment and alveolar bone loss. 4,5,9-14

Periodontal disease is one of the main causes of tooth loss worldwide. ${ }^{15-20}$ Several studies have demonstrated the effectiveness of periodontal therapy in reducing the rate of tooth loss ${ }^{21-24}$ and established the importance of patient compliance with maintenance therapy and adequate oral hygiene measures in achieving these reductions. ${ }^{25-28}$ However, few studies have examined risk indicators associated with tooth loss due to periodontal reasons. ${ }^{29-33}$ As the "true" endpoint in periodontal therapy, ${ }^{34}$ identification of factors associated with increased risk for tooth loss due to periodontal disease may aid in strengthening the evidence for these factors as risk indicators of periodontal disease severity.

Therefore, the aim of this study was to examine the association of some of the documented risk indicators for periodontal disease severity (age, gender, smoking, and medical and dental histories) with the risk for tooth loss due to periodontal reasons. 


\section{MATERIALS AND METHODS}

This was a cross-sectional, multicenter study of consecutive cases examining the factors associated with tooth loss due to periodontal reasons in Kuwait. In the health services system employed in Kuwait, patients seek primary medical and dental care in one of six health districts based on their area of residency. As such, twenty four general dental practice centers (four centers from each of the six districts) were randomly chosen for patient recruitment in an attempt to provide a sample representative of the entire country. Dentists in these centers were interviewed and informed of the objectives of the study and asked to participate, and those working in 21 of the 24 centers agreed to take part, for a response rate of $87.5 \%$. These 21 centers also represented $25 \%$ of the 81 general practice dental centers in Kuwait.

Inclusion criteria for this study were all consecutively seen adult patients (18 years of age or older) in each participating center in need of one or more teeth extracted during the study period. The study protocol was submitted for review by the ethical review committee of the Faculty of Dentistry, Kuwait University prior to commencement of the project, and informed consent was obtained from all study participants.

Dentists were requested to complete a specially designed study form on every extraction they were to perform within a 1-month period. The study form documented the patient's age, gender, past medical history, dental maintenance visit history, toothbrushing frequency, smoking history, the tooth/teeth extracted, and the reason for the performed extraction(s).

The criteria for selecting the reason for extraction given to all participating dentists was a modification of that used in previous studies. ${ }^{16,35}$ Participating dentists were instructed to consider the extraction performed for periodontal reasons if the extracted tooth or teeth had two or more of the following: loss of $>50 \%$ of remaining bone support as evidenced by radiographs, advanced clinical attachment loss $(\geq 7$ $\mathrm{mm}$ ), grades 2 or 3 mobility, suppuration, or Class III furcation involvement for molar teeth. Other options given were either severe caries, root fracture, failed endodontic therapy, tooth malposition, or patient refusal of alternative treatment. A space was also provided for listing other reasons of extraction not included in the study form. Third molar extractions were not included in this study because indications for the removal of third molars are generally different from those of other teeth. ${ }^{36,37}$

Essentially, the dentist's judgment of the reason for extraction was the primary deciding factor because validation of the reasons for extraction was not possi- ble in this study. For this reason, and because it was anticipated that some dentists might select multiple reasons for the loss of one tooth, an additional question was included in the survey to attempt to standardize the responses. Because previous studies have reported that caries and periodontal disease were the two main reasons for tooth loss, the final question in the study form asked the dentist to decide whether the loss of each particular tooth was due mostly to caries, periodontal disease, or other reasons, and answers to this question were used in the analysis. Study forms were collected by the principal investigator at the end of the study period for each center. The study was performed during July 2004.

\section{Statistical Analysis}

The main outcome variable was tooth loss due to periodontal disease versus other reasons (caries, failed endodontic therapy, root fracture, tooth malposition, or patient refusal of alternative therapy) pooled together in one group. Study forms with duplicate, missing, or multiple answers were excluded, and only those where a clear indication for tooth loss was due to periodontal or other reasons were used in the analysis. In cases of multiple extractions, cases were excluded if some teeth were extracted for one reason and others extracted for a different reason to avoid tooth-dependent effects.

Means and frequency distributions were calculated for all background and outcome study variables. Differences in age and mean number of extracted teeth between the two groups (extractions due to periodontal or other reasons) were compared to the Student $t$ test. Associations of the categorical background variables (age range, gender, smoking status, medical history problems, dental maintenance visit history, and toothbrushing frequency) with reasons for tooth loss were examined using the chi-square test.

Multivariate analysis using binary logistic regression was performed to examine which factors found significant with univariate analyses remained as such after adjusting for confounding factors. The regression model used the dependent variable of reason for tooth loss dichotomized into loss due to periodontal reasons versus loss due to other reasons. Variables entered in the model were age range $(\leq 35$ or $>35$ years), gender (male or female), medical history problems (diabetes mellitus, hypertension, cardiovascular disease, rheumatoid arthritis, stroke, asthma, renal or hepatic problems, and osteoporosis), smoking status (current or past smoker versus never smoked), dental maintenance visit history (never versus yes), and toothbrush use (never versus yes). Adjusted odds ratios (OR) and corresponding 95\% confidence intervals were generated for all significant variables. The significance level used was $P<0.05$. 


\section{RESULTS}

No subjects refused to have their data used in the study. Out of 1,898 study forms returned, 123 forms (236 teeth) were excluded from the analysis because multiple reasons were selected for the extraction or extractions performed. A total of 1,775 patients had 3,694 teeth extracted during the 30-day study period, for an overall mean tooth loss rate of $2.1 \pm 0.8$ teeth per patient. The demographic characteristics and smoking status of patients are summarized in Table 1. The mean age of all patients was $39.8 \pm 0.3$ years (range $=18$ to 83 years), and patients losing their teeth for periodontal reasons were significantly older than those losing their teeth for other reasons (48.9 \pm 0.5 versus $35.8 \pm 0.3$ years, respectively; $P<0.001)$. Although fewer patients lost their teeth due to periodontal disease than for other reasons (30.5\% versus $69.5 \%$, respectively), more teeth per patient were lost due to periodontal reasons than for other causes $(2.8 \pm 0.2$ versus $1.8 \pm 0.1$, respectively; $P<0.001)$.

Males comprised $55.4 \%$ of the sample, and a greater proportion of them lost their teeth to periodontal reasons than did females (33.2\% versus $27.1 \%$, respectively; $P<0.01$ ). Current and past smokers accounted for $30.8 \%$ of all patients. Fourteen patients had full-mouth extractions (extraction of all remaining 28 teeth). Periodontal reasons were responsible for the extraction in the majority of these cases $(85.7 \% ; P<0.001)$.

\section{Table I.}

\section{Patient Demographics and Smoking History}

\begin{tabular}{|c|c|c|c|}
\hline Variable & Periodontal Disease & Other Reasons* & Total \\
\hline Mean age $( \pm$ SE) & $48.9( \pm 0.5)^{\dagger}$ & $35.8( \pm 0.3)$ & $39.8( \pm 0.3)$ \\
\hline Number of patients (\%) & $54 \mid(30.5)$ & $1234(69.5)$ & 1775 \\
\hline Number of extracted teeth & $1653(44.7)$ & $204 \mid(55.3)$ & 3694 \\
\hline Teeth lost per patient (mean \pm SE) & $2.8(0.2)^{\dagger}$ & $1.8(0.1)$ & $2.1(0.8)$ \\
\hline \multicolumn{4}{|l|}{ Gender } \\
\hline Male (\%) & $327(33.2)^{\ddagger}$ & $657(66.8)$ & $984(55.4)$ \\
\hline Female (\%) & $214(27.1)$ & $577(72.9)$ & $791(44.6)$ \\
\hline \multicolumn{4}{|l|}{ Smoking status $§$} \\
\hline Current/past smoker (\%) & 155 (29.5) & $379(31.4)$ & $534(30.8)$ \\
\hline Never smoked (\%) & $370(70.5)$ & $827(86.6)$ & | 197 (69.2) \\
\hline
\end{tabular}

The most common medical history finding in all patients was diabetes mellitus (19.2\%) followed by hypertension (13.6\%). Other medical problems were present in smaller proportions (Fig. 1).

Only $12.9 \%$ of all patients reported having had a dental prophylaxis or periodontal maintenance visit within the 6 months preceding the study, whereas a substantial percentage (39.1\%) reported they have never had such a visit (Fig. 2). Similarly, the selfreported toothbrushing frequency of the patients was low, with only $16.2 \%$ brushing their teeth twice or more daily, whereas $59.8 \%$ either never brushed their teeth or used a toothbrush irregularly (Fig. 3).

Mandibular and maxillary molars were the most commonly extracted teeth in all patients and were extracted more commonly for reasons other than periodontal disease $(P<0.001$; Table 2$)$. Conversely, maxillary and mandibular anterior teeth were extracted more for periodontal disease than for other reasons $(P<0.001)$. No significant differences were found in the reasons for extraction of premolar teeth.

On the other hand, when only the teeth extracted for periodontal reasons were analyzed by tooth type (Fig. 4), mandibular and maxillary molars were also the teeth most commonly extracted. The teeth least likely to be lost due to periodontal reasons were the mandibular and maxillary canines.

Associations between background study variables and tooth loss to periodontal reasons are presented in Table 3. Grouping of the patients 35 years of age or younger versus those older than 35 years revealed significantly different patterns of tooth loss. Although few teeth were extracted for periodontal reasons in younger patients, periodontal disease accounted for the majority of tooth extractions in patients older than 35 years $(57.3 \%$ of teeth were lost for periodontal reasons compared to $42.7 \%$ lost for other reasons; $P<0.001)$. Gender differences were not significant $(P=0.387)$. Several medical history problems significantly associated with tooth loss for periodontal reasons, including diabetes, hypertension, cardiovascular disease, stroke, rheumatoid arthritis, asthma, renal and hepatic problems, and osteoporosis $(P<0.05)$. Smoking history did not reach a statistically significant level 


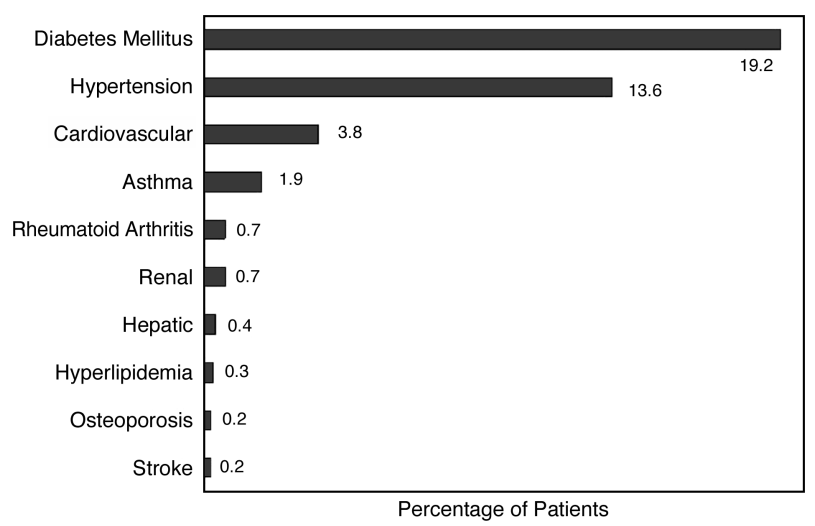

Figure I.

Medical history findings.

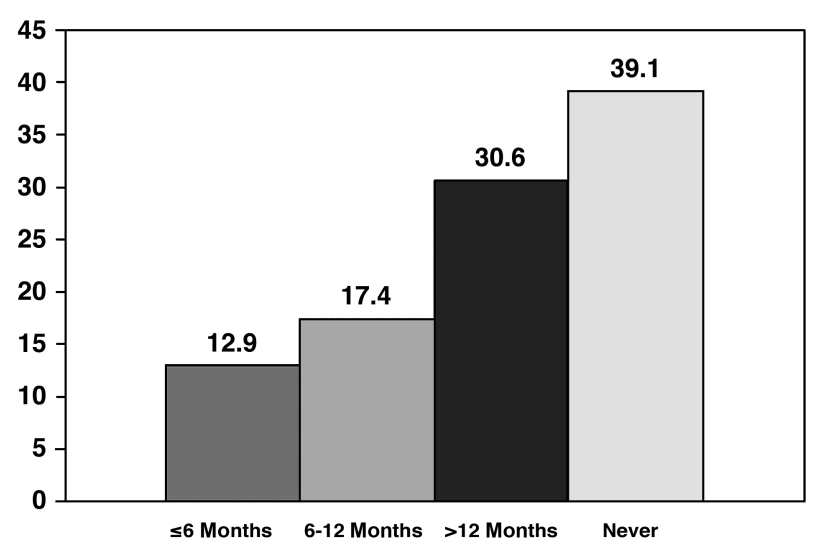

Figure 2.

Last dental prophylaxis or periodontal maintenance visit.

$(P=0.144)$. Comparison of dental maintenance history and toothbrushing frequency revealed that never having a maintenance visit and never using the toothbrush were significantly associated with tooth loss for periodontal reasons $(P<0.001)$. Additionally, anterior tooth types (canines and incisors) were significantly associated with tooth loss due to periodontal disease $(P<0.001)$.

Binary logistic regression analysis results with the adjusted odds ratios and corresponding 95\% confidence intervals are presented in Table 4 . The model correctly classified $75.7 \%$ of the subjects into the two reason categories of extraction due to periodontal disease or other reasons and had a significance level of $P<0.001$. Factors significantly associated with tooth loss due to periodontal reasons after adjusting for confounding variables were age $>35$ years $(\mathrm{OR}=$ $3.45)$, male gender $(\mathrm{OR}=1.42)$, never having periodontal maintenance $(\mathrm{OR}=1.48)$, never using the

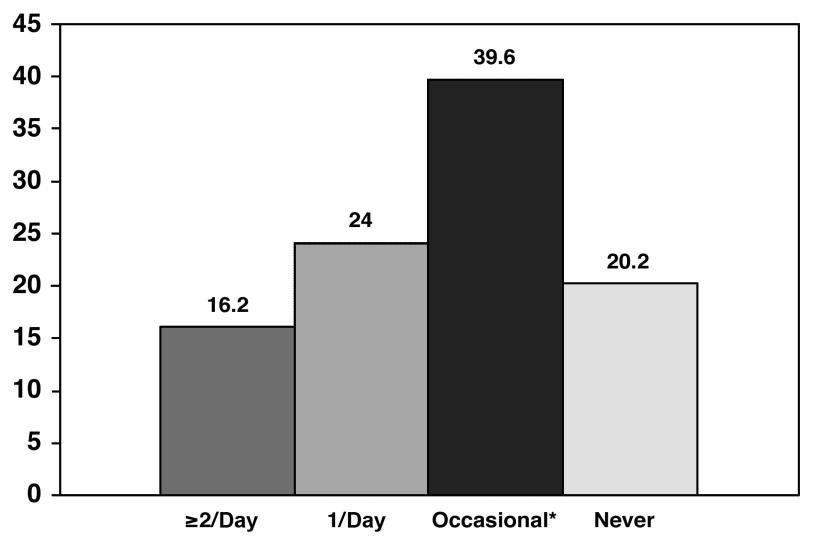

Figure 3.

Toothbrushing frequency. *Occasional toothbrushing: less than one time per day, but sometimes using a toothbrush.

toothbrush $(\mathrm{OR}=1.81)$, current or past smoking $(\mathrm{OR}=1.56)$, anterior tooth type $(\mathrm{OR}=3.23)$, and the presence of the following medical conditions: diabetes mellitus $(O R=2.64)$, hypertension $(O R=1.73)$, or rheumatoid arthritis $(O R=4.19)$. Variables eliminated from the final model due to lack of significance were cardiovascular disease, stroke, asthma, renal problems, hepatic problems, and osteoporosis.

\section{DISCUSSION}

Risk assessment is an important component of modern dental therapy. ${ }^{3}$ Identification of subjects with the greatest risk for periodontal disease severity and progression is essential for the proper allocation of preventive and therapeutic measures to those individuals who would benefit the most from such measures. This is especially important because the prevalence of severe forms of periodontal disease has been shown to be concentrated in a specific group of patients exhibiting the greatest rates of tooth and attachment loss. ${ }^{27,38-41}$ As such, this study was undertaken to examine the association between several reported risk indicators for periodontal disease severity and tooth loss due to periodontal reasons.

Tooth loss for periodontal reasons was significantly associated with age $(\mathrm{OR}=3.45)$ for patients older than 35 years. This confirms previous investigations that associated older age with attachment loss 5,11 and tooth loss for periodontal reasons. ${ }^{16,19,20,42,43}$ This finding is, however, in contrast to the results of some studies suggesting caries was the main reason for tooth loss in all age groups. ${ }^{44,45}$ This may be due to differences in criteria used in these studies or the age ranges of the patients studied because strikingly different patterns of tooth loss were seen in this study when grouping the patients into those older than 35 years of age versus those 35 years old or younger. 
Table 2.

\section{Reason for Extraction of Different Tooth Types}

\begin{tabular}{|c|c|c|c|c|}
\hline Tooth Type & $\begin{array}{c}\text { Periodontal } \\
\text { Disease } \\
\text { n (\%) }\end{array}$ & $\begin{array}{c}\text { Other } \\
\text { Reasons* } \\
\text { n (\%) }\end{array}$ & $P$ Value $^{\dagger}$ & $\begin{array}{l}\text { Total } \\
\text { n (\%) }\end{array}$ \\
\hline Maxillary molar & $333(38.4)$ & $535(61.6)$ & $<0.001$ & $868(23.5)$ \\
\hline Maxillary premolar & $280(42.4)$ & $381(57.6)$ & NS & $661(17.9)$ \\
\hline Maxillary anterior ${ }^{\ddagger}$ & $242(72.5)$ & $92(27.5)$ & $<0.001$ & $334(9.0)$ \\
\hline Mandibular molar & $338(31.4)$ & $738(68.6)$ & $<0.001$ & $1076(29.1)$ \\
\hline Mandibular premolar & $232(48.7)$ & $244(51.3)$ & NS & $476(12.9)$ \\
\hline Mandibular anterior $\ddagger$ & $228(81.7)$ & $5 \mid(18.3)$ & $<0.001$ & $279(7.6)$ \\
\hline
\end{tabular}

* Other reasons: caries, failed endodontic therapy, root fracture, tooth malposition, or patient refusal of alternative treatment.

$\dagger$ Chi-square test.

‡ Canine, lateral incisor, or central incisor.

NS $=$ not statistically significant

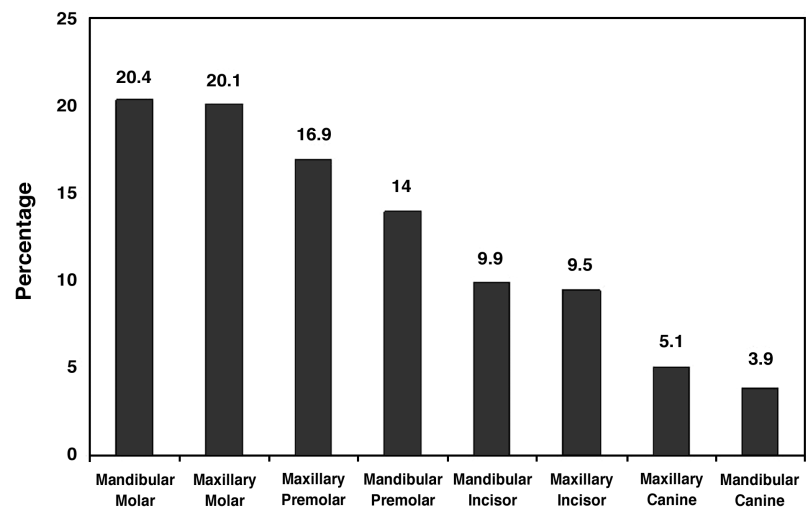

Figure 4.

Teeth lost due to periodontal disease.

This study also indicated that although only $30.5 \%$ of the patients lost their teeth due to periodontal reasons, these patients lost more teeth per patient than patients losing their teeth for other reasons ( 2.8 versus 1.8 teeth). This confirms previous findings that periodontal disease, although it may be responsible for tooth loss in fewer patients, is responsible for the loss of more teeth than any other cause. ${ }^{46}$ Periodontal reasons were also responsible for the majority of full-mouth extractions in this study (12 of 14 cases), which agrees with previous suggestions of periodontal disease leading to more cases of complete tooth loss in highly susceptible individuals. ${ }^{25,27}$

Male gender was also significantly associated with tooth loss for periodontal reasons $(\mathrm{OR}=1.42)$, which is in agreement with previous investigations ${ }^{47,48}$ This odds ratio is also very close to that reported by Grossi et al. $^{5}$ for male gender and risk for attachment loss (1.36).
Current and past smokers were also more likely to have tooth loss due to periodontal reasons than patients who had never smoked (OR = 1.56). The effects of smoking on periodontal disease severity and tooth loss are well documented. $4,5,10,49,50$

Stronger associations were found in the Erie county studies between smoking and attachment loss and radiographic alveolar bone loss. ${ }^{4,5}$ Differences may be due to the high prevalence of smoking patients in those studies, where $60.7 \%$ of the patients were smokers compared to $30.8 \%$ of patients in this study. Additionally, quantification of smoking into categories of heavy, moderate, or light smokers was not possible in this study because data regarding the number of cigarettes smoked per day and years smoking were lacking for a significant portion of smoking patients. Stronger associations may have been found had this information been available.

Several medical history problems were significantly associated with increased risk for tooth loss due to periodontal reasons (Table 4). Patients with diabetes were more likely to have a tooth lost due to periodontal reasons than non-diabetic patients (OR $=2.64)$. The association between diabetes and periodontal disease is also well established. ${ }^{9,14,33,51,52}$ It is worth noting that the odds ratio for tooth loss in patients with diabetes in this study (2.64) is also close to that reported by Grossi et al. ${ }^{5}$ for attachment loss and diabetes (2.32).

Other medical history problems associated with tooth loss for periodontal reasons were hypertension $(\mathrm{OR}=1.73)$ and rheumatoid arthritis $(\mathrm{OR}=4.19)$. An association between tooth loss and an increased risk for hypertension in postmenopausal women has been reported, ${ }^{53}$ but the association between periodontal disease and hypertension is otherwise not well established. Similarly, a strong association was found between rheumatoid arthritis and tooth loss for periodontal reasons $(\mathrm{OR}=4.19)$. Although the association between periodontal disease and rheumatoid arthritis is still not clearly established, results of this study support other findings of a possible association between the two diseases. ${ }^{54-56}$ Although osteoporosis, cardiovascular disease, stroke, asthma, renal problems, and liver problems showed significant associations with tooth loss due to periodontal reasons 
Table 3.

\section{Associations of Demographic, Medical, and Dental Variables With Reasons for Tooth Loss}

\begin{tabular}{|c|c|c|c|c|}
\hline Variable & Periodontal Disease & Other Reasons* & $P$ Value $^{\dagger}$ & Total \\
\hline \multicolumn{5}{|l|}{ Age } \\
\hline$\leq 35$ years & $15 \mid(\mid 4.1)$ & $920(85.9)$ & & 1396 \\
\hline$>35$ years & $1502(57.3)$ & $|12|(42.7)$ & $<0.001$ & 2298 \\
\hline \multicolumn{5}{|l|}{ Gender } \\
\hline Male & $881(45.0)$ & $1077(55.0)$ & & 1958 \\
\hline Female & $772(44.5)$ & $964(55.5)$ & 0.387 & 1736 \\
\hline \multicolumn{5}{|l|}{ Medical history problems } \\
\hline Diabetes mellitus & $812(71.9)$ & $317(28.1)$ & $<0.001$ & 1129 \\
\hline Hypertension & $692(72.7)$ & $260(27.3)$ & $<0.001$ & 952 \\
\hline Cardiovascular & $255(71.6)$ & $101(28.4)$ & $<0.001$ & 356 \\
\hline Stroke & $46(95.8)$ & $2(4.2)$ & $<0.001$ & 48 \\
\hline Rheumatoid arthritis & $97(86.6)$ & $15(13.4)$ & $<0.001$ & 112 \\
\hline Asthma & $105(72.4)$ & $40(27.6)$ & $<0.001$ & 145 \\
\hline Renal & $22(62.9)$ & $13(37.1)$ & 0.03 & 35 \\
\hline Hepatic & $41(80.4)$ & $10(19.6)$ & $<0.001$ & 51 \\
\hline Osteoporosis & $39(79.6)$ & $10(20.4)$ & $<0.001$ & 49 \\
\hline \multicolumn{5}{|l|}{ Smoking status ${ }^{\ddagger}$} \\
\hline Current/past smoker & $539(43.6)$ & $698(56.4)$ & & 1237 \\
\hline Never smoked & $1097(45.5)$ & $1315(54.5)$ & 0.144 & 2414 \\
\hline \multicolumn{5}{|l|}{ History of maintenance ${ }^{\ddagger}$} \\
\hline Yes & $562(33.4)$ & 1122 (66.6) & & 1684 \\
\hline Never & $1084(54.5)$ & $905(45.5)$ & $<0.001$ & 1989 \\
\hline \multicolumn{5}{|l|}{ Toothbrush use } \\
\hline Yes & $780(33.4)$ & I 554 (66.6) & & 2334 \\
\hline Never & $837(64.2)$ & $487(35.8)$ & $<0.001$ & 1360 \\
\hline \multicolumn{5}{|l|}{ Tooth type ${ }^{\S}$} \\
\hline Posterior & | $18 \mid$ (38.4) & $1898(61.6)$ & & 3079 \\
\hline Anterior & $472(76.7)$ & I 43 (23.3) & $<0.001$ & 615 \\
\hline
\end{tabular}

* Caries, failed endodontic therapy, root fracture, tooth malposition, or patient refusal of alternative treatment.

$\dagger$ Chi-square test.

* Numbers do not add up to the total number of teeth $(3,694)$ due to missing cases.

$\S$ Posterior: molar or premolar; anterior: canine, lateral incisor, or central incisor.

in univariate analysis (Table 3 ), regression analysis failed to associate any of these medical conditions to the outcome variable. This illustrates the importance of multivariate analysis using logistic regression methods in eliminating the confounding effects of interrelated variables. ${ }^{57,58}$

Dental maintenance visit history and toothbrush use were significantly associated with risk for tooth loss due to periodontal reasons. Patients who have never had a dental prophylaxis or periodontal maintenance visit and those who never brushed their teeth had odds ratios of 1.48 and 1.81 for tooth loss due to periodontal reasons, respectively. This corresponds to the strong research evidence supporting the role of pa- tient compliance with periodontal maintenance and self-performed oral hygiene practices in maintaining periodontal health. 21,26,28,59-63

Regarding tooth types, anterior teeth were more likely to be extracted for periodontal reasons than posterior teeth $(\mathrm{OR}=3.23)$. This finding has been reported previously. ${ }^{15,19,64,65}$ A possible explanation that has been proposed for this pattern is that because lower anterior teeth are less susceptible to caries than other teeth, they are more likely to remain in the dentition in older patients where periodontal disease becomes the more common reason for extraction. ${ }^{42,66}$ This is also supported by the observation in this study of anterior teeth being extracted mostly in cases of multiple and full-mouth extractions (data not shown). However, caution must be taken when interpreting these results. As illustrated in Figure 4, when the teeth lost for periodontal reasons were analyzed, mandibular and maxillary molars were extracted much more commonly than other teeth, whereas the mandibular and maxillary canines were extracted significantly less commonly than other teeth. This agrees with studies evaluating tooth loss in periodontal patients only, ${ }^{23}$ where mandibular canines were the least extracted of all tooth types.

Several factors that have been previously associated with risk for attachment and alveolar bone loss in periodontal patients were examined in this study for their possible association as risk indicators for periodontal disease severity using an additional outcome measure, tooth loss. This aimed to validate the association of these factors by associating them with the proposed "true" endpoint in dentistry. ${ }^{34}$ The finding of similar associations of risk between the same variables when evaluated by tooth loss or the other "surrogate" endpoints of attachment and 
Table 4.

\section{Logistic Regression Analysis of Factors Associated With Tooth Loss for Periodontal Reasons*}

\begin{tabular}{|c|c|c|c|}
\hline Variable & $\mathrm{B}(\mathrm{SE})$ & OR & $95 \% \mathrm{Cl}$ \\
\hline Age $>35$ years & $1.24(0.11)$ & 3.45 & (2.79 to 4.26$)$ \\
\hline Male gender & $0.35(0.10)$ & 1.42 & (1.17 to 1.73$)$ \\
\hline Diabetes mellitus & $0.97(0.09)$ & 2.64 & (2.19 to 3.18$)$ \\
\hline Hypertension & $0.55(0.11)$ & 1.73 & $(1.41$ to 2.13$)$ \\
\hline Rheumatoid arthritis & $1.43(0.34)$ & 4.19 & $(2.17$ to 8.11$)$ \\
\hline Never having periodontal maintenance & $0.39(0.09)$ & 1.48 & ( 1.23 to 1.78$)$ \\
\hline Never brushing & $0.59(0.10)$ & 1.81 & (1.49 to 2.20$)$ \\
\hline Current or past smoker & $0.44(0.10)$ & 1.56 & $(1.28$ to 1.91$)$ \\
\hline Anterior tooth type & $1.17(0.12)$ & 3.23 & (2.57 to 4.05 ) \\
\hline
\end{tabular}

* All variables were significant at $P<0.001$; variables that were eliminated from the final model: cardiovascular disease, stroke, asthma, renal problems, hepatic problems, and osteoporosis; significance of the model: chi-square $=1192.3 ; P<0.001$

$\mathrm{B}=$ regression coefficient.

alveolar bone loss may indicate the informativeness of these surrogates about the true endpoint in at least one aspect, that of shared risk. ${ }^{67}$ However, whether these surrogate endpoints can capture the effects of treatment on the reduction of tooth loss, as required for their validation as informative endpoints, ${ }^{67}$ is difficult to infer from these results.

This was a cross-sectional study of a sample of patients needing teeth extracted. Therefore, causal associations between the examined variables and tooth loss due to periodontal disease and their role as true risk factors cannot be ascertained without the use of longitudinal follow-up data. However, cross-sectional studies such as this do provide useful data on risk indicators or markers by determining associations between specific attributes of risk and disease outcome, allowing the examination of the identified risk indicators in future longitudinal and interventional investigations that can ascertain their role as risk factors. ${ }^{5}$

Limitations of the study design include the challenge of obtaining a representative sample and the possibility of selection bias. The patients evaluated in this study were all seen at government-operated dental centers in Kuwait. Therefore, this study could only evaluate patients who sought dental care, not those in need of dental treatment. Accordingly, the prevalence of severe periodontal disease cannot be estimated, and associations of tooth loss due to periodontal disease with the examined risk indicators are only applicable to this subsample of the population. Government-operated dental centers were utilized in this study because in the health care system employed in Kuwait, the majority of patients seek primary dental care at such centers, and only a small percentage is seen in private practice clinics. General dental practice centers were also chosen to avoid a potential bias favoring overrepresentation of periodontal patients had the study been performed in periodontal specialist clinics.

The applicability of these results to other populations in other parts of the world may be rightfully questioned, because genetic susceptibility to periodontal diseases has been demonstrated, ${ }^{68}$ and other environmental and background factors such as education level were not evaluated. On the other hand, the prevalence of tooth loss due to periodontal reasons in this representative sample of adult dental patients in Kuwait (30.5\% of all patients and $44.7 \%$ of all teeth) was remarkably similar to most studies performed around the world, including studies in France, ${ }^{16}$ Germany, ${ }^{43}$ England, ${ }^{69}$ Singapore, ${ }^{20}$ Japan, ${ }^{64}$ Canada, ${ }^{19}$ and the U.S. ${ }^{46}$ This may support the validity of these risk indicators and their association with tooth loss for periodontal disease in other parts of the world and may warrant comparative investigations in other populations.

\section{REFERENCES}

1. American Academy of Periodontology. Epidemiology of periodontal diseases (position paper). J Periodontol 1996;67:935-945.

2. American Academy of Periodontology. The pathogenesis of periodontal diseases. J Periodontol 1999;70:457-470.

3. Beck JD. Risk revisited. Community Dent Oral Epidemiol 1998;26:220-225.

4. Grossi SG, Genco RJ, Machtei EE, et al. Assessment of risk for periodontal disease. II. Risk indicators for alveolar bone loss. J Periodontol 1995;66:23-29.

5. Grossi SG, Zambon JJ, Ho AW, et al. Assessment of risk for periodontal disease. I. Risk indicators for attachment loss. J Periodontol 1994;65:260-267.

6. Kocher T, Schwahn C, Gesch D, et al. Risk determinants of periodontal disease - An analysis of the Study of Health in Pomerania (SHIP 0). J Clin Periodontol 2005;32:59-67.

7. Machtei EE, Hausmann E, Dunford R, et al. Longitudinal study of predictive factors for periodontal disease and tooth loss. J Clin Periodontol 1999;26:374-380.

8. Page RC, Martin J, Krall EA, Mancl L, Garcia R. Longitudinal validation of a risk calculator for periodontal disease. J Clin Periodontol 2003;30:819-827. 
9. Emrich LJ, Shlossman M, Genco RJ. Periodontal disease in non-insulin-dependent diabetes mellitus. $J$ Periodontol 1991;62:123-131.

10. Haber J, Wattles J, Crowley M, Mandell R, Joshipura K, Kent RL. Evidence for cigarette smoking as a major risk factor for periodontitis. J Periodontol 1993;64: 16-23.

11. Ismail AI, Morrison EC, Burt BA, Caffesse RG, Kavanagh MT. Natural history of periodontal disease in adults: Findings from the Tecumseh Periodontal Disease Study, 1959-87. J Dent Res 1990;69: 430-435.

12. Machtei EE, Dunford R, Hausmann E, et al. Longitudinal study of prognostic factors in established periodontitis patients. J Clin Periodontol 1997;24:102109.

13. Moore PA, Weyant RJ, Mongelluzzo MB, et al. Type 1 diabetes mellitus and oral health: Assessment of periodontal disease. J Periodontol 1999;70:409-417.

14. Shlossman M, Knowler WC, Pettitt DJ, Genco RJ. Type 2 diabetes mellitus and periodontal disease. $J$ Am Dent Assoc 1990;121:532-536.

15. Ainamo J, Sarkki L, Kuhalampi ML, Palolampi L, Piirto O. The frequency of periodontal extractions in Finland. Community Dent Health 1984;1:165-172.

16. Cahen PM, Frank RM, Turlot JC. A survey of the reasons for dental extractions in France. $J$ Dent Res 1985;64:1087-1093.

17. Corbet EF, Davies WI. Reasons given for tooth extraction in Hong Kong. Community Dent Health 1991;8: $121-130$.

18. Haddad I, Haddadin K, Jebrin S, Ma'ani M, Yassin O. Reasons for extraction of permanent teeth in Jordan. Int Dent $J$ 1999;49:343-346.

19. Murray H, Locker D, Kay EJ. Patterns of and reasons for tooth extractions in general dental practice in Ontario, Canada. Community Dent Oral Epidemiol 1996;24:196-200.

20. Ong G, Yeo JF, Bhole S. A survey of reasons for extraction of permanent teeth in Singapore. Community Dent Oral Epidemiol 1996;24:124-127.

21. Becker W, Berg L, Becker BE. The long term evaluation of periodontal treatment and maintenance in 95 patients. Int $J$ Periodontics Restorative Dent 1984; 4(2):54-71.

22. Chace R Sr., Low SB. Survival characteristics of periodontally-involved teeth: A 40-year study. J Periodontol 1993;64:701-705.

23. Hirschfeld L, Wasserman B. A long-term survey of tooth loss in 600 treated periodontal patients. J Periodontol 1978;49:225-237.

24. McFall WT Jr. Tooth loss in 100 treated patients with periodontal disease. A long-term study. J Periodontol 1982;53:539-549.

25. Becker W, Becker BE, Berg LE. Periodontal treatment without maintenance. A retrospective study in 44 patients. J Periodontol 1984;55:505-509.

26. Ramfjord SP. Maintenance care for treated periodontitis patients. J Clin Periodontol 1987;14:433-437.

27. Tonetti MS, Steffen P, Muller-Campanile V, Suvan J, Lang NP. Initial extractions and tooth loss during supportive care in a periodontal population seeking comprehensive care. J Clin Periodontol 2000;27:824831.

28. Wilson TG Jr., Glover ME, Malik AK, Schoen JA, Dorsett D. Tooth loss in maintenance patients in a private periodontal practice. $J$ Periodontol 1987;58: 231-235.

29. Holm G. Smoking as an additional risk for tooth loss. $J$ Periodontol 1994;65:996-1001.

30. Kocher T, Konig J, Dzierzon U, Sawaf H, Plagmann HC. Disease progression in periodontally treated and untreated patients - A retrospective study. J Clin Periodontol 2000;27:866-872.

31. Konig J, Plagmann HC, Ruhling A, Kocher T. Tooth loss and pocket probing depths in compliant periodontally treated patients: A retrospective analysis. $J$ Clin Periodontol 2002;29:1092-1100.

32. McGuire MK, Nunn ME. Prognosis versus actual outcome IV. The effectiveness of clinical parameters and IL-1 genotype in accurately predicting prognoses and tooth survival. J Periodontol 1999;70:49-56.

33. Moore PA, Weyant RJ, Mongelluzzo MB, et al. Type 1 diabetes mellitus and oral health: Assessment of tooth loss and edentulism. J Public Health Dent 1998;58: 135-142.

34. Hujoel PP, DeRouen TA. A survey of endpoint characteristics in periodontal clinical trials published 19881992, and implications for future studies. J Clin Periodontol 1995;22:397-407.

35. McCaul LK, Jenkins WM, Kay EJ. The reasons for extraction of permanent teeth in Scotland: A 15-year follow-up study. Br Dent J 2001;190:658-662.

36. Liedholm R, Knutsson K, Lysell L, Rohlin M. Mandibular third molars: Oral surgeons' assessment of the indications for removal. $\mathrm{Br} J$ Oral Maxillofac Surg 1999;37:440-443.

37. Lysell L, Rohlin M. A study of indications used for removal of the mandibular third molar. Int $J$ Oral Maxillofac Surg 1988;17:161-164.

38. Griffiths GS, Wilton JM, Curtis MA, et al. Detection of high-risk groups and individuals for periodontal diseases. Clinical assessment of the periodontium. J Clin Periodontol 1988;15:403-410.

39. Johnson NW, Griffiths GS, Wilton JM, et al. Detection of high-risk groups and individuals for periodontal diseases. Evidence for the existence of high-risk groups and individuals and approaches to their detection. J Clin Periodontol 1988;15:276-282.

40. Tonetti MS, Muller-Campanile V, Lang NP. Changes in the prevalence of residual pockets and tooth loss in treated periodontal patients during a supportive maintenance care program. J Clin Periodontol 1998;25: 1008-1016.

41. Wilton JM, Griffiths GS, Curtis MA, et al. Detection of high-risk groups and individuals for periodontal diseases. Systemic predisposition and markers of general health. J Clin Periodontol 1988;15:339-346.

42. Ong G. Periodontal disease and tooth loss. Int Dent $J$ 1998;48(3, Suppl.1):233-238.

43. Reich E, Hiller KA. Reasons for tooth extraction in the western states of Germany. Community Dent Oral Epidemiol 1993;21:379-383.

44. Bailit HL, Braun R, Maryniuk GA, Camp P. Is periodontal disease the primary cause of tooth extraction in adults? J Am Dent Assoc 1987;114:40-45.

45. Caldas AF Jr., Marcenes W, Sheiham A. Reasons for tooth extraction in a Brazilian population. Int Dent $J$ 2000;50:267-273.

46. Phipps KR, Stevens VJ. Relative contribution of caries and periodontal disease in adult tooth loss for an HMO dental population. J Public Health Dent 1995;55: 250-252. 
47. Fardal O, Johannessen AC, Linden GJ. Tooth loss during maintenance following periodontal treatment in a periodontal practice in Norway. $J$ Clin Periodontol 2004;31:550-555.

48. Locker D, Slade GD, Murray H. Epidemiology of periodontal disease among older adults: A review. Periodontol 2000 1998;16:16-33.

49. American Academy of Periodontology. Tobacco use and the periodontal patient (position paper). J Periodontol 1999;70:1419-1427.

50. Johnson GK, Hill M. Cigarette smoking and the periodontal patient. J Periodontol 2004;75:196-209.

51. American Academy of Periodontology. Diabetes and periodontal diseases (position paper). J Periodontol 2000;71:664-678.

52. Nelson RG, Shlossman M, Budding LM, et al. Periodontal disease and NIDDM in Pima Indians. Diabetes Care 1990;13:836-840.

53. Taguchi A, Sanada M, Suei Y, et al. Tooth loss is associated with an increased risk of hypertension in postmenopausal women. Hypertension 2004;43: 1297-1300

54. Molloy J, Wolff LF, Lopez-Guzman A, Hodges JS. The association of periodontal disease parameters with systemic medical conditions and tobacco use. J Clin Periodontol 2004;31:625-632.

55. Mercado FB, Marshall RI, Bartold PM. Inter-relationships between rheumatoid arthritis and periodontal disease. A review. J Clin Periodontol 2003;30:761772 .

56. Slade GD, Offenbacher S, Beck JD, Heiss G, Pankow JS. Acute-phase inflammatory response to periodontal disease in the US population. J Dent Res 2000; 79:49-57.

57. Moerbeek M, van Breukelen GJ, Berger MP. A comparison between traditional methods and multilevel regression for the analysis of multicenter intervention studies. J Clin Epidemiol 2003;56:341-350.

58. Bowalekar SK. Statistics in medical research - III. Correlation and regression analysis. J Postgrad Med 1993;39:235-243.
59. American Academy of Periodontology. Supportive periodontal therapy (SPT). J Periodontol 1998;69: 502-506

60. Löe H, Theilade E, Jensen SB. Experimental gingivitis in man. J Periodontol 1965;36:177-187.

61. Ramfjord SP, Morrison EC, Burgett FG, et al. Oral hygiene and maintenance of periodontal support. $J$ Periodontol 1982;53:26-30.

62. Suomi JD, Doyle J. Oral hygiene and periodontal disease in an adult population in the United States. $J$ Periodontol 1972;43:677-681.

63. Suomi JD, Greene JC, Vermillion JR, Doyle J, Chang JJ, Leatherwood EC. The effect of controlled oral hygiene procedures on the progression of periodontal disease in adults: Results after third and final year. $J$ Periodontol 1971;42:152-160.

64. Morita M, Kimura T, Kanegae M, Ishikawa A, Watanabe $T$. Reasons for extraction of permanent teeth in Japan. Community Dent Oral Epidemiol 1994;22: 303-306.

65. Sayegh A, Hilow H, Bedi R. Pattern of tooth loss in recipients of free dental treatment at the University Hospital of Amman, Jordan. J Oral Rehabil 2004;31: 124-130.

66. Kay EJ, Blinkhorn AS. The reasons for the extraction of various tooth types in Scotland. J Dent 1987;15:30-33.

67. Hujoel PP, Löe H, Anerud A, Boysen H, Leroux BG. The informativeness of attachment loss on tooth mortality. J Periodontol 1999;70:44-48.

68. Kornman KS, Crane A, Wang HY, et al. The interleukin1 genotype as a severity factor in adult periodontal disease. J Clin Periodontol 1997;24:72-77.

69. Agerholm DM, Sidi AD. Reasons given for extraction of permanent teeth by general dental practitioners in England and Wales. Br Dent J 1988;164:345-348.

Correspondence: Dr. Khalaf F. Al-Shammari, Ministry of Health, Kuwait, P.O. Box 758, Jahra, Kuwait, 01009. Fax: 965-4562346; e-mail: khalsham@hotmail.com.

Accepted for publication April 3, 2005. 